\title{
SUPPLEMENTING COGNITIVE AGING: A SELECTIVE REVIEW OF THE EFFECTS OF GINKGO BILOBA AND A NUMBER OF EVERYDAY NUTRITIONAL SUBSTANCES.
}

\section{Louise A. Brown}

Division of Psychology, Glasgow Caledonian University, Glasgow, UK

\section{Leigh M. Riby}

\section{Jonathon L. Reay}

Division of Psychology, Northumbria University, Newcastle upon Tyne, UK

To cite:

Brown, L.A., Riby, L.M., \& Reay, J.L. (2009). Supplementing cognitive aging: a selective review of the effects of ginkgo biloba and a number of everyday nutritional substances. Experimental Aging Research, 36, 105-122. DOI:10.1080/03610730903417960 


\section{ACKNOWLEDGEMENTS}

The authors wish to thank an anonymous reviewer for their helpful comments on an earlier version of this manuscript. 


\begin{abstract}
This review concerns a number of substances which have been receiving much attention, particularly in the media, for their potential to protect against age-related cognitive decline, and a focus is placed upon recent findings. Omega-3 fatty acids appear to play important roles in preserving neuronal structure and function and minimizing cognitive decline, while antioxidant vitamins $\mathrm{C}$ and $\mathrm{E}$ appear to be particularly beneficial for combating age-related oxidative stress when administered in combination. Fruit and vegetable polyphenols also offer great potential, although most research thus far has involved rodents. Finally, there is mixed evidence regarding the cognitive enhancing properties of Ginkgo biloba, and the B vitamins folate and cobalamin, with all of these requiring further investigation.
\end{abstract}

Keywords: Cognition; Aging; Ageing; n-3 fatty acids; flavonoids; blueberries; vitamin B-9; vitamin B-12. 
Advancing age is accompanied by the decline of cognitive abilities such as perceptual speed, reasoning, episodic memory, and working memory. Conversely, well-practised tasks or those involving a knowledge base (e.g., vocabulary, semantic memory) show less decline, while some abilities appear to remain stable throughout life (e.g., autobiographical memory, emotional processing, and automatic memory processes; for a review, see Hedden \& Gabrieli, 2004). Crucially, those cognitive abilities which do suffer age-related decline impact significantly upon the everyday lives of older adults. For example, older adults exhibit reduced performance on tests indexing the instrumental activities of daily living (ADL) involving tasks such as taking medications, meal preparation, and telephone usage (Burton, Strauss, Hultsch, \& Hunter, 2006). Furthermore, older adults who have been diagnosed with mild cognitive impairment (MCI), a borderline state between age-related cognitive decline and mild dementia, have been found to exhibit more severe deficits on most elements of complex ADL, including finding items in the home, keeping appointments, remembering information from newspapers or the television, and talking about recent events (Perneczky et al., 2006). It is therefore clear that age-related cognitive impairment may impact significantly on the everyday lives of older adults.

In recent years there has been increasing interest, particularly within the media, in the variety of interventions which may help to improve cognitive performance in older age, such as nutritional supplementation, cognitive training, and physical activity. Since a number of nutritional supplements have shown the potential to slow or even reverse age-related cognitive decline, and have received much media attention in this light, it is timely that the present article reviews the facilitative effects of these substances in older age. The reviewed substances include both macroand micronutrients and one herbal extract which has shown promise. Specifically, omega-3 fatty 
acids, antioxidant vitamins $\mathrm{C}$ and $\mathrm{E}$, the $\mathrm{B}$ vitamins folate and cobalamin, fruit and vegetable polyphenols, and ginkgo biloba are discussed.

\section{Omega-3 Fatty Acids}

Omega-3 fatty acids are a type of polyunsaturated fatty acid, derived from various fish and plants (e.g., salmon, mackerel, tuna, soybeans, pumpkin seeds, and walnuts), which have received research attention for emphasizing the potential benefits of use with older adults. It is believed that changes in the typical 'European diet' have resulted in a decline in the natural intake of omega-3 fatty acids (Sanders, 2000), which may have implications in terms of age-related health risks. As well as cognitive dysfunction, various health risks of deficient dietary omega-3 have been widely reported (e.g., cardiovascular disease). At the cellular level, deficiencies in omega-3 can affect the chemical composition of neuronal cell membranes and influence neurotransmission processes (Mazza, Pomponi, Janiri, Bria, \& Mazza, 2007). Importantly, the cognitive benefits of adequate dietary omega-3 have been linked to two compounds; namely eicosapentaenoic acid (EPA) and docosahexaenoic acid (DHA), both largely derived from fish oil and particularly important for maintaining healthy cell function (Yuen, Sander, Fluegel, \& Patsalos, 2005).

Correlational studies have investigated the relationship between fish and seafood consumption and dementia, and it has been found that the intake of fish or seafood at least once a week is associated with a decreased risk of developing dementia and the accompanying cognitive decline (Barberger-Gateau et al., 2002). Indeed, the consequences of consuming one fish meal per week and two or more fish meals per week is reported to be a $10 \%$ and $13 \%$ reduction in the rate of cognitive decline, respectively (Morris, Evans, Tangney, Bienias, \& Wilson, 2005). However, two limitations of these studies need to be considered. First, work of this nature would benefit from 
greater specificity of the fish or seafood consumed, since omega-3 fatty acid concentration varies between fish and seafood products (for estimates, see Mozaffarian \& Rimm, 2006). Second, it is not possible to determine the precise nature of cognitive functions moderated by the intake of omega-3, as global measures of cognition have typically been utilized. A recent study by Dangour et al. (2009) revealed positive associations between fish consumption (via assessment of frequency and type of fish consumed), and a range of cognitive outcomes including memory and executive function, in 867 cognitively healthy older adults aged 70-79 years. Notably, however, the relationships were attenuated after adjustments for factors such as education and psychological health.

Additional insights into the protective effect of polyunsaturated fatty acids come from the findings that neuronal cell membrane compositions exhibit a decrease in Alzheimer's disease (AD; e.g., Guan, Soderberg, Sindelar, \& Edlund, 1994) and that, in AD patients, a specific deficit may exist in DHA levels in the hippocampus, a key structure involved in learning and memory (Lukiw et al., 2005). Overall, it has been highlighted that DHA plays an important role in cognitive functioning since it is critical to cell survival (Mazza et al., 2007; see also Lukiw \& Bazan, 2008). Studies have investigated DHA and cognitive performance in MCI and, in a study by Kotani et al. (2006), cognitive dysfunction (memory and attention) brought about by MCI or organic brain damage was found to be improved by $240 \mathrm{mg} / \mathrm{day}$ of a combination of two fatty acids, namely arachidonic acid (AA; omega-6) and DHA (omega-3); however, no such improvement was found for AD patients. Kroger et al. (2009), who also adjusted for the influence of apolipoprotein E (APOE) allele type, found no relationship between erythroycte membrane omega-3 fatty acids and risk of dementia. On the other hand, though, Whalley et al. (2008) found a positive association between erythrocyte membrane omega-3 fatty acids and cognitive performance in non-demented 
older adults. This association remained after adjustment for factors including intelligence at age 11 years, but existed only in the absence of the APOE $\varepsilon 4$ allele, suggesting a gene $\mathrm{x}$ environment interaction in this population.

The inclusion of AA in the study by Kotani et al. (2006) brings into question the potential role for omega-6 fatty acids, derived mainly from vegetable oil (Mazza et al., 2007). However, in contrast with the decrease in omega-3 intake, omega-6 has actually shown an increase in western diets (e.g., see Ruxton, Reed, Simpson, \& Millington, 2007; Sanders, 2000). Also, as Youdim, Martin, and Joseph (2000) have highlighted, although omega-6 fatty acids are also present, the brain is particularly rich in omega-3 fatty acids such as DHA (see also Dangour, Sibson, \& Fletcher, 2004). Because it is important to achieve the correct balance of these substances for healthy brain function, and due to the evidence of altered intake, the current focus should be placed upon supplementation with omega-3 fatty acids.

Indeed, work involving rodents suggests that cognitive behavior is related to DHA status (Moriguchi, Greiner, \& Salem, 2000) and that treatment with DHA can reduce the decline of such abilities in an AD model (Hashimoto et al., 2002). This study, which showed the beneficial effect of DHA on episodic memory (avoidance learning ability) in $\mathrm{AD}$ model rats, also found an associated increase in DHA cortico-hippocampal levels and a decrease in products associated with neuronal cell death (Hashimoto et al., 2002). Additionally, relative to omega-3 adequate rats, those which were deficient in neuronal DHA were able to perform simple learning tasks but were impaired regarding performance on a more complex, higher-order learning task (Catalan et al., 2002). Crucially, the concentrations of DHA and AA have been found to be decreased in the hippocampus of older rats, as compared with younger animals, while enriching the diet with omega-3 fatty acids has been found to result in full restoration of DHA and partial restoration of AA (McGahon, Martin, 
Horrobin, \& Lynch, 1999). At the neuronal level, age-related decreases in long-term potentiation (LTP; an impressive form of synaptic plasticity which is thought to be related to learning and/or memory) and glutamate release were also found to be reversed in this study.

From the evidence reviewed above it appears that omega-3 fatty acids do exhibit great potential for providing positive cognitive outcomes in older age, and authorities in the UK have recommended levels of intake equivalent to 1-2 portions of oily fish per week (Sanders, 2000). However, some important caveats remain. For example, while a wide range of health benefits of DHA exist, sufficient attention is not always paid to the recommended dosage of the now widely available fish oil supplements. In fact, excessive intake of DHA is capable of disturbing neuronal function (Horrocks \& Yeo, 1999). Additionally, there has also been concern over the contaminants found in some seafood, such as mercury. The benefits associated with seafood consumption do, however, seem to outweigh the potential risks (for a review, see Mozaffarian \& Rimm, 2006).

\section{Vitamins $C$ and $E$}

The brain is particularly vulnerable to the processes of oxidative stress and the free radical action which can ultimately result in neuronal cell death (Butterfield et al., 2002). Indeed, free radicalmediated damage has been implicated in a number of age-related disorders such as $\mathrm{AD}$, and Parkinson's and Huntington's diseases. Antioxidant substances such as vitamins C and E have the ability to inhibit oxidative damage and have therefore been investigated for their potential to slow or reverse age-related cognitive decline.

In a key prospective study, plasma levels of ascorbic acid (vitamin C) in older adults aged 65 years and over were correlated with measurements taken 22 years earlier (Perrig, Perrig, \& Stahelin, 1997). Plasma antioxidant levels were found to be stable between the two measurement periods, but 
higher levels at both time points were associated with better performance in a number of memory skills (episodic and semantic memory). The relationship between vitamin E intake (assessed by a food frequency questionnaire) and the rate of cognitive decline in adults aged 65 years and over has also been considered. In that study, during a three year period, a 36\% reduction in cognitive decline was observed between those individuals categorised as 'high' (median $=387.4 \mathrm{IU} / \mathrm{day}$ ) compared to 'low' (median = $6.8 \mathrm{IU} /$ day) vitamin E consumers (Morris, Evans, Bienias, Tangney, \& Wilson, 2002). The assessed cognitive domains included immediate and delayed recall, and perceptual speed, and global performance as measured by the Mini-Mental State Examination (MMSE).

An important observation in previous research, however, is the synergistic effect of combining vitamins $\mathrm{C}$ and $\mathrm{E}$, with evidence suggesting an association between supplementation of combined vitamins $\mathrm{C}$ and $\mathrm{E}$ and reduced occurrence of AD (Zandi et al., 2004). Synergism was evident in this study due to a protective effect of combined vitamin E (at least 400 IU) and multivitamins (containing at least $500 \mathrm{mg}$ of vitamin $\mathrm{C}$ ), but the absence of protection by vitamin $\mathrm{C}$, vitamin $\mathrm{E}$, or multivitamins taken alone. A further longitudinal study reported a reduction in cognitive decline, as measured by the modified MMSE, with combined use of vitamins $\mathrm{C}$ and $\mathrm{E}$ and/or multivitamins (Maxwell, Hicks, Hogan, Basran, \& Ebly, 2005; dosage and duration data not available). While this study was unable to find a protective effect of antioxidant vitamins for the incidence of $A D$, a protective effect for vascular cognitive impairment was identified.

A recent study has shown that higher cognitive function and a slower rate of cognitive decline were associated with total vitamin $\mathrm{C}$ intake alone, and in combination with vitamin $\mathrm{E}$, in older adults (aged 65 years or over) during a seven year period, as assessed by the modified MMSE (Wengreen et al., 2007). The authors concluded that the intake of vitamins $\mathrm{C}$ and $\mathrm{E}$ may indeed delay cognitive decline associated with the aging process. Nonetheless, the results are by no means 
unequivocal; for example, another study found no such association between vitamins $\mathrm{C}$ (mean $=$ $302 \mathrm{mg} /$ day $)$ and $\mathrm{E}($ mean $=187 \mathrm{IU} /$ day $)$ supplementation and a reduced risk of developing $\mathrm{AD}$ over a mean follow-up period of 4 years (Luchsinger, Tang, Shea, \& Mayeux, 2003). However, methodological difficulties should be highlighted since, most notably, relatively low sample size and imprecision in the assessment of dietary vitamin intake was problematic in the latter study (Luchsinger et al., 2003).

Overall, the evidence seems to be more reliable for combined antioxidant vitamin intake providing protection against age-related cognitive decline. One review, however, which assessed the general health (including cognitive) benefits of micronutrient supplementation concluded that there is no support for the use of antioxidant vitamin or mineral supplements in well-nourished older adults. Additionally, the research has warned of the adverse effects of micronutrient supplementation administered at high levels for extended periods of time (Dangour et al., 2004).

\section{B Vitamins}

Folate $\left(\mathrm{B}_{9}\right)$ and cobalamin $\left(\mathrm{B}_{12}\right)$ are two of the $\mathrm{B}$ vitamins which are currently being investigated for their potential to combat age-related decline, and there is a particular focus on their ability to prevent the onset of dementia through their interaction with the neurotoxic substance homocysteine (e.g., see Clarke, 2008; Schulz, 2007). Folate is easily absorbed from the diet, but deficiency is common at all ages due to "poor diet, malabsorption or alcoholism, or from the use of certain drugs" (Clarke, 2008, p.75). In contrast, cobalamin deficiency is associated with malabsorption due to digestive disorders such as pernicious anaemia, occurring mainly in older adults, and can result in irreversible neurological disorders such as peripheral neuropathy (Clarke, 2008; Rébeillé et al., 2007). Liver is a particularly rich source of both these micronutrients; however, for folate, the main 
sources in adults are green leafy vegetables while, for cobalamin, the sources are meat, eggs, and dairy products (Rébeillé et al., 2007).

Folate and cobalamin deficiencies both have the accumulation of homocysteine in common [however, cobalamin deficiency also results in increased levels of methylmalonic acid, allowing differentiation between the two deficiencies (Rébeillé et al., 2007)]. Furthermore, clinical trials have identified homocysteine as a risk factor for vascular disease, and cognitive dysfunction or dementia, with elevated levels being detectable years before the dementia presents. For example, Dimopoulos et al. (2006) showed that a sample of individuals with dementia had lower levels of folate and cobalamin, and higher levels of homocysteine, in comparison with a group of healthy controls. A prospective study over a 4.5 year period also found that homocysteine is a risk factor for dementia or cognitive impairment without dementia, and that plasma cobalamin can reduce this risk (Haan et al., 2007). Notably, however, Haan et al. found no association between red blood cell folate and dementia or cognitive impairment, although they stated that this may have been influenced by a lack of low folate values. Li et al. (2009) found no independent association between plasma total homocysteine and MMSE performance in AD patients but, similarly, for the vast majority of participants, homocysteine concentration fell within the normal range. On the other hand, Kado et al. (2005) did find folate, but not cobalamin, to be independently predictive of cognitive decline over a 7 year period in high functioning adults aged 70 to 79 years. In adults aged 65 years and above, over a 4 year period, elevated homocysteine levels were also found to be associated with an increased risk of both dementia and $\mathrm{AD}$, and low levels of folate, but not cobalamin, to be an independent predictor of both dementia and AD (Ravaglia et al., 2007). In another prospective study, Morris et al. (2006) found no association between folate intake or cobalamin intake and risk of developing $\mathrm{AD}$ over a 4 year period. While this study took into 
account possible confounding by niacin and vitamin E intake levels, it did rely upon participant estimations of intake via a food frequency questionnaire. Finally, a recent study by Tassino, Campos, and Guerra (2009) showed that homocysteinemia predicted a relatively low proportion (4\%) of the variance in cognitive function in a group of low-income older Brazilian adults, however it is possible that the predictive power would have been larger if more sensitive outcome measures had been used.

It is important to note that some authors argue that elevated homocysteine is not a causative factor for dementia, but rather that it provides a marker of vascular disease (e.g., see Seshadri, 2006). Indeed, Mooijaart et al. (2005) showed that, although elevated homocysteine levels and reduced folate levels were associated with cognitive impairment in older adults aged 85 years, these factors did not predict an increased rate of cognitive decline over the following 4 years. Notably, cobalamin was neither associated with cognitive impairment at baseline, nor predictive of rate of cognitive decline thereafter. These authors suggested that low folate levels and high homocysteine levels could be a consequence of cognitive impairment due to poor eating habits rather than a contributory cause. Tangney, Tang, Evans, and Morris (2009), who investigated levels of methylmalonic acid, a more specific marker of cobalamin deficiency than homocysteine, found that higher serum concentrations of methylmalonic acid and lower cobalamin were both associated with faster rates of cognitive decline over a 6 year period. Furthermore, Feng, Li, Yap, Kua, and Ng (2009) recently showed that the positive association between cobalamin and cognitive function is moderated by APOE $\varepsilon 4$ status, with a stronger association present in $\varepsilon 4$ carriers.

Two recent randomized, double-blind, placebo-controlled trials have been carried out to investigate the possible cognitive benefits of folate and cobalamin supplementation. Durga et al. (2007) administered adults, aged 50-70 years, either $800 \mu \mathrm{g} / \mathrm{day}$ of oral folic acid or a placebo for a 
period of 3 years. The participants were expected to benefit from the homocysteine-lowering effects of folic acid, with plasma total homocysteine levels greater than $13 \mu \mathrm{mol} / \mathrm{L}$ (additionally, those with levels $>26 \mu \mathrm{mol} / \mathrm{L}$ were excluded, where concentrations were possibly due to factors other than suboptimal folate level). Global cognitive performance and, more specifically, the domains of memory, information processing speed, and sensorimotor speed, were improved by folic acid supplementation, while the complex speed and word fluency domains showed no benefit. Eussen et al. (2006) investigated the effects of 24 wk supplementation with high doses of cobalamin (1000 $\mu \mathrm{g} /$ day), or with cobalamin $(1000 \mu \mathrm{g} /$ day) plus folic acid $(400 \mu \mathrm{g} / \mathrm{d})$, in older adults with a mild cobalamin deficiency, aged 70 years or above. Cobalamin supplementation corrected the mild deficiency and reduced homocysteine levels by $16 \%$, while cobalamin plus folic acid supplementation increased red blood cell folate concentrations, and decreased homocysteine levels by $36 \%$. In this study, neither cobalamin supplementation alone, nor cobalamin with folate supplementation, were found to improve cognitive performance as measured by an extensive battery of tests, which assessed a number of domains including attention, memory, and sensorimotor speed. While this brings into question the efficacy of cobalamin supplementation, the relatively short-term duration of the supplementation may have limited the effects. A similar trial carried out over the longer term would therefore be welcomed.

While there is clear evidence for an association between folate and cobalamin levels and cognitive performance in older age, trials have thus far provided limited evidence of the cognitive benefits of folate, and disappointing results for cobalamin. The evidence appears more convincing for folate supplementation, such that there is clear ground for further evaluation. Indeed, further investigation is particularly relevant, given that excessive intakes of folate in older adults can result 
in delayed diagnosis of cobalamin deficiency and therefore more rapid progression of the related neuropathy or cognitive impairment (Clarke, 2008).

\section{Fruit and Vegetable Polyphenols}

Flavonoids, present in colourful flowers and fruits, comprise the largest group of polyphenols, which are substances found in fruits, vegetables, and some plants. Polyphenols can protect against cell death and some possess anti-inflammatory properties. Because of this, they could be suitably used in conditions such as $\mathrm{AD}$, which is characterized by oxidative stress and inflammation, and in which the level of antioxidant defence becomes depleted (Butterfield et al., 2002). Furthermore, the combination of antioxidant and anti-inflammatory polyphenolic compounds found in fruit and vegetables, although not involved in the food plant's primary metabolism, increase its ability to survive, and therefore may offer humans beneficial effects during the aging process (for a review, see Joseph, Shukitt-Hale, \& Casadesus, 2005). Indeed, a large prospective study of the relationship between fruit and vegetable consumption (extending over a period of 10-16 years), indicated that vegetable intake is related to reduced cognitive decline (Kang, Ascherio, \& Grodstein, 2005). This was particularly the case for green leafy vegetables (e.g., spinach and romaine lettuce) and cruciferous vegetables (e.g., broccoli and cauliflower). In addition, the protective effects of dietary polyphenols have also been reported for non-fruit and vegetable sources; for example, it has been shown that the intake of flavonoids (known to be present in wine) is negatively related to the incidence of AD (Commenges et al., 2000).

Research with rodents has greatly contributed to the growing body of evidence indicating the positive outcomes of fruit and vegetable polyphenols. For example, rats supplemented with either strawberry extracts $(9.5 \mathrm{gm} / \mathrm{kg})$, spinach extracts $(6.4 \mathrm{gm} / \mathrm{kg})$, or vitamin $\mathrm{E}(500 \mathrm{IU} / \mathrm{kg})$ over the 
long-term (8 months) exhibited retarded onset of age-related neuronal and cognitive deficits (Joseph et al., 1998). It may be worth noting that, because the spinach condition resulted in the greatest overall benefits, the authors questioned whether the phytochemicals present in fruit and vegetables may offer some other mechanism of protection over and above the antioxidant and antiinflammatory ones (Joseph et al., 1998; 2005). Further research showed that 8-week supplementation with spinach $(9.1 \mathrm{gm} / \mathrm{kg})$, strawberry $(14.8 \mathrm{gm} / \mathrm{kg})$, or blueberry $(18.6 \mathrm{gm} / \mathrm{kg})$ improved age-related cognitive deficits, but that only blueberry supplementation improved motor function (Joseph et al., 1999). In a further study utilizing a rodent model, it was found that supplementation with antioxidant-rich blueberries $(20 \mathrm{gm} / \mathrm{kg})$ from 4 to 12 months of age normalised spatial memory deficits in AD (Joseph et al., 2003), and it has been argued that the pattern of results suggests the involvement of phytochemicals in mechanisms of protection other than antioxidant ones, such as alterations in neuronal signalling (Joseph et al., 2005; see also Shukkitt-Hale, Lau, \& Joseph, 2009). Polyphenolic compounds present in blueberries are able to cross the blood-brain barrier and, following blueberry supplementation in rats, have been found in a number of brain areas including the hippocampus. Additionally, the presence of polyphenolic compounds has been positively correlated with cognitive performance (Andres-Lacueva et al., 2005). Indeed, recent work by Papandreou et al. (2009) showed that short-term supplementation with $60 \mathrm{mg} / \mathrm{kg}$ of wild blueberry extract over the short-term (7 days) resulted in enhanced learning and memory performance which was related not only to higher brain antioxidant properties but also to inhibition of acetylcholinesterase activity. Other evidence suggests that the beneficial effect of blueberries on spatial memory is mediated, at least in part, by their effect on hippocampal plasticity via increased neurogenesis (Casadesus et al., 2004), and these authors stated that it remains to be seen whether or not the cognitive enhancement of blueberries would also be observed in humans. It 
is important that treatments be developed which can mimic the actions of blueberries in rats in order to help slow, or even reverse, age-related cognitive and neuronal decline.

Similar to the beneficial effect of blueberries, Concord grape juice, another substance high in antioxidant and anti-inflammatory properties, has been shown to exert a positive, dose-response effect upon cognitive and motor function in aged rats (Shukitt-Hale, Carey, Simon, Mark, \& Joseph, 2006). In this study cognitive enhancement was found with $10 \%$ grape juice, while enhancement in motor performance was found with a 50\% concentration. The authors interpreted these and previous (Joseph et al., 1999) results as showing that enhancements of motor performance are more difficult to achieve and require larger amounts of polyphenols. However, it remains questionable why the $50 \%$ grape juice did not exert an effect on cognitive deficits and the authors have found this difficult to explain. They have speculated that the effect of grape juice may exhibit an optimal dosage on some outcome measures. The variety of effects exerted by the polyphenols present in fruits and vegetables may reflect a synergistic effect beyond simply antioxidant or antiinflammatory ones and, in the example of the Concord grape, the whole may be greater than the sum of its parts (Shukitt-Hale et al., 2006). This argument may also explain why some studies discussed above have failed to observe beneficial effects of just one or two antioxidant vitamins.

\section{Ginkgo Biloba}

The health benefits relating to the ingestion of numerous herbal products, and their active phytochemicals, have been a matter of debate for many years. Many of these studies have utilized rodent models and a range of methodologies in human populations (e.g., epidemiological, crosssectional, and prospective). Particularly relevant to the present review are the purported protective effects against natural aging (both relating to a decline in cognitive ability and health status) or 
against those pathologies where aging is a major risk factor (e.g., dementia), and only those studies which have utilized placebo-controlled, double-blind protocols can be seen as clinically relevant. One such herbal supplement, Ginkgo biloba, has been studied extensively, with regard to its effects on both behavior and physiological parameters (Maclennan, Darlington, \& Smith, 2002). Ginkgo biloba is of particular interest as the active chemicals (flavonoids, biflavonoids and terpenes; Gold, Cahill, \& Wenk, 2002) have been shown to exert a broad range of biochemical and pharmacological actions. These include antioxidant and free radical scavenging effects, as well as hemodynamic and neurotransmitter effects, all of which may be relevant to aging and age-related disorders (Maclennan et al., 2002). These studies may go some way to validating the current status of the herb in Germany and France. In these countries it is currently prescribed for the treatment of cerebral insufficiency, and is recommended both for age-related cognitive decline and for slowing the progress of neurodegenerative disorders such as AD. However, in the UK, Canada, and the USA, it is marketed as an over-the-counter food supplement.

Despite Ginkgo's current status and the plethora of in vitro/animal data, research relating to the clinical efficacy of the substance in human populations is not clear. For example, individual studies have reported improved cognitive performance following 26 weeks (Le Bars, Kieser, \& Itil, 2000) and 52 weeks (Le Bars et al., 1997) of Ginkgo supplementation (120 mg/day) in an AD population. Similarly, a recent review suggested that there is a small, but significant, effect of 3 to 6 months of treatment with 120 to $140 \mathrm{mg} /$ day on objective measures of cognitive function in $\mathrm{AD}$ (Oken, Storzbach, \& Kaye, 1998). However, others studies have shown no positive impact upon natural brain aging in healthy older adults $(60-82$ years) following $120 \mathrm{mg} / \mathrm{day}$ for 6 weeks. In addition, a recent review showed that there was no systematic and clinically meaningful effect of Ginkgo on any cognitive measure employed, involving patients with a mild or moderate stage of 
dementia (van Dongen, van Rossum, Kessels, Sielhorst, \& Knipschild, 2000). Indeed, in a recent meta-analysis, Birks and Grimley Evans (2009, p.2) concluded "evidence that Ginkgo has predictable and clinically significant benefit for people with dementia or cognitive impairment is inconsitent and unreliable". Although attempts to bring clarity should be applauded, such a negative conclusion may be somewhat premature and may be attributed to the disparity in methodologies, extracts investigated, and populations studied, let alone the fact that there are few clinical studies available for review. As stated by the authors, out of the 36 available studies, only 30 possessed adequate methodologies and, of these, 15 contribute very few data. Additionally, although the effects of Ginkgo biloba were reported in terms of global outcomes (e.g., global, cognitive function, ADLs, mood and emotional function) around a 12 week treatment period, it is apparent that there is very little similarity between the majority of studies in terms of design, duration, assessment method, study population, and the extract investigated to allow specific conclusions to be drawn. Thus, while there is a wealth of evidence relating to the physiological effects of Ginkgo biloba which may underlie human health and behavior, the evidence relating to its clinical efficacy remains unclear and warrants further investigation.

\section{Summary}

Given the fact that human beings are living longer and that aging is a major risk factor for disease progression (particularly in $\mathrm{AD}$ ), it is not unexpected that a greater proportion of the population will show varying degrees of cognitive decline. As this 'new' population grows we will be faced with untold economic costs, in terms of care facilities, family responsibility, and drug development. It therefore seems timely to investigate further the potential interventions employing the use of nutritional substances. This review has focused on compounds which have received a great deal of 
attention in the media, particularly those which may slow the aging process. Omega-3 fatty acids have consistently been shown to offer protection against cognitive decline, such that consumption of 1-2 portions of oily fish per week is now recommended. Fruit and vegetable polyphenols also offer great promise; however, much of the evidence is based upon research using rodents rather than human subjects. Antioxidant vitamins $\mathrm{C}$ and $\mathrm{E}$, the B vitamins folate and cobalamin, and the herbal extract Ginkgo biloba, have produced more mixed findings: combined vitamin $\mathrm{C}$ and $\mathrm{E}$ intake may offer more protective power, while limited benefits of Ginkgo biloba and the B vitamins have been observed. Overall, the potential clinical efficacy of such substances is clear, but further, well-controlled clinical trials are required before reliable conclusions can be drawn.

\section{REFERENCES}

Andres-Lacueva, C., Shukitt-Hale, B., Galli, R. L., Jauregui, O., Lamuela-Raventos, R. M., \& Joseph, J. A. (2005). Anthocyanins in aged blueberry-fed rats are found centrally and may enhance memory. Nutritional Neuroscience, 8, 111-120.

Barberger-Gateau, P., Letenneur, L., Deschamps, V., Pérès, K., Dartigues, J., \& Renaud, S. (2002). Fish, meat, and risk of dementia: a cohort study. British Medical Journal, 325, 932-933.

Birks, J., \& Grimley Evans, J. (2009). Ginkgo biloba for cognitive impairment and dementia. Cochrane Database of Systematic Reviews, 1, CD003120.

Burton, C. L, Strauss, E., Hultsch, D. F., \& Hunter, M. A. (2006). Cognitive functioning and everyday problem solving in older adults. Clinical Neuropsychologist, 20, 432-452.

Butterfield, D. A., Castegna, A., Pocernich, C. B., Drake, J., Scapagnini, G., \& Calabrese, V. (2002). Nutritional approaches to combat oxidative stress in Alzheimer's disease. Journal of Nutritional Biochemistry, 13, 444-461. 
Casadesus, G., Shukitt-Hale, B., Stellwagen, H. M., Zhu, X., Lee, H., Smith, M. A., et al. (2004). Modulation of hippocampal plasticity and cognitive behaviour by short-term blueberry supplementation in aged rats. Nutritional Neuroscience, 7, 309-316.

Catalan, J., Moriguchi, T., Slotnick, B., Murthy, M., Greiner, R. S., \& Salem, N. (2002). Cognitive deficits in docosahexaenoic acid-deficient rats. Behavioural Neuroscience, 116, 1022-1031.

Clarke, R. (2008). B-vitamins and prevention of dementia. Proceedings of the Nutrition Society, 67, 75-81.

Commenges, D., Scotet, V., Renaud, S., Jacqmin-Gadda, H., Barberger-Gateau, P., \& Dartigues, J.F. (2000). Intake of flavonoids and risk of dementia. European Journal of Epidemiology, 16, $357-363$.

Dangour, A. D., Allen, E., Elbourne, D., Fletcher, A., Richards, M., \& Uauy, R. (2009). Fish consumption and cognitive function among older people in the UK: Baseline data from the OPAL study. Journal of Nutrition, Health, \& Aging, 13, 198-202.

Dangour, A. D., Sibson, V. L., \& Fletcher, A. E. (2004). Micronutrient supplementation in later life: Limited evidence for benefit. Journals of Gerontology: Biological Sciences and Medical Sciences, 59A, 659-673.

Dimopoulos, N., Piperi, C, Salonicioti, A., Psarra, V., Gazi., F., Nounopoulos, C., et al. (2006). Association of cognitive impairment with plasma levels of folate, vitamin $\mathrm{B}_{12}$ and homocysteine in the elderly. In Vivo, 20, 895-900.

Durga, J., van Boxtel, M. P. J., Schouten, E. G., Kok, F. J., Jolles, J., Katan, M. B., et al. (2007). Effect of 3-year folic acid supplementation on cognitive function in older adults in the FACIT trial: a randomised, double blind, controlled trial. Lancet, 369, 208-216. 
Eussen, S. J., de Groot, L. C., Joosten, L. W., Bloo, R. J., Clarke, R., Ueland, P. M., et al. (2006). Effect of oral vitamin B-12 with or without folic acid on cognitive function in older people with mild vitamin B-12 deficiency: a randomized, placebo-controlled trial. American Journal of Clinical Nutrition, 84, 361-370.

Feng, L., Li, J. L., Yap, K. B., Kua, E. H., \& Ng, T. P. (2009). Vitamin B-12, apolipoprotein E genotype, and cognitive performance in community-living older adults: evidence of a genemicronutrient interaction. American Journal of Clinical Nutrition, 89, 1263-1268.

Gold, P. E., Cahill, L., \& Wenk, G.L. (2002). Ginkgo biloba: A cognitive enhancer? Psychological Science, 13, S2-S11.

Guan, Z. Z, Soderberg, M., Sindelar, P., \& Edlund, C. (1994). Content and fatty acid composition of cardiolipin in the brain of patients with Alzheimer's disease. Neurochemistry International, 25, 295-300.

Haan, M. N., Miller, J. W., Aiello, A. E., Whitmer, R. A., Jagust, W. J., Mungas, D. M., et al. (2007). Homocysteine, B vitamins, and the incidence of dementia and cognitive impairment: results from the Sacramento Area Latino Study on Aging. American Journal of Clinical Nutrition, 85, 511-517.

Hashimoto, M., Hossain, S., Shimada, T., Sugioka, K., Yamasaki, H., Fujii, Y., et al. (2002). Docosahexaenoic acid provides protection from impairment of learning ability in Alzheimer's disease model rats. Journal of Neurochemistry, 81, 1084-1091.

Hedden, T., \& Gabrieli, J. D. E. (2004). Insights into the ageing mind: A view from cognitive neuroscience. Nature Reviews Neuroscience, 5, 87-96.

Horrocks, L. A., \& Yeo, Y. K. (1999). Health benefits of docosahexaenoic acid (DHA). Pharmacological Research, 40, 211-225. 
Joseph, J. A., Denisova, N. A., Arendash, G., Gordon, M., Diamond, D., Shukitt-Hale, B., et al. (2003). Blueberry supplementation enhances signaling and prevents behavioral deficits in an Alzheimer Disease model. Nutritional Neuroscience, 6, 153-162.

Joseph, J. A., Shukitt-Hale, B., \& Casadesus, G. (2005). Reversing the deleterious effects of aging on neuronal communication and behavior: Beneficial properties of fruit polyphenolic compounds. American Journal of Clinical Nutrition, 81, 313S-316S.

Joseph, J. A., Shukitt-Hale, B., Denisova, N. A., Bielinksi, D., Martin, A., McEwen, J. J., et al. (1999). Reversals of age-related declines in neuronal signal transduction, cognitive and motor behavioral deficits with blueberry, spinach, or strawberry dietary supplementation. Journal of Neuroscience, 19, 8114-8121.

Joseph, J. A., Shukitt-Hale, B., Denisova, N. A., Prior, R. L., Cao, G., Martin, A., et al. (1998). Long-term dietary strawberry, spinach, or vitamin E supplementation retards the onset of agerelated neuronal signal-transduction and cognitive behavioural deficits. Journal of Neuroscience, 18, 8047-8055.

Kado, D. M., Karlamangla, A. S., Huang, M., Troen, A., Rowe, J. W., \& Selhub, J. (2005). Homocysteine versus the vitamins folate, $\mathrm{B}_{6}$, and $\mathrm{B}_{12}$ as predictors of cognitive function and decline in older high-functioning adults: MacArthur Studies of Successful Aging. American Journal of Medicine, 118, 161-167.

Kang, J. H., Ascherio, A., \& Grodstein, F. (2005). Fruit and vegetable consumption and cognitive decline in aging women. Annals of Neurology, 57, 713-720.

Kotani, S., Sakaguchi, E., Warashina, S., Matsukawa, N., Ishikura, Y, Kiso, Y, et al. (2006). Dietary supplementation of arachidonic and docosahexaenoic acids improves cognitive dysfunction. Neuroscience Research, 56, 159-164. 
Kroger, E., Verreault, R., Carmichael, P., Lindsay, J., Julien, P., Dewailly, E., et al. (2009). Omega3 fatty acids and risk of dementia: the Canadian Study of Health and Aging. American Journal of Clinical Nutrition, 90, 184-192.

Le Bars, P. L., Katz, M. M., Berman, N., Itil, T. M., Freedman, A. M., \& Schatzberg, A. F. (1997). A placebo-controlled, double-blind, randomized trial of an extract of Ginkgo biloba for dementia. Journal of the American Medical Association, 278, 1327-1332.

Le Bars, P. L., Kieser, M., \& Itil, K. (2000). A 26-week analysis of a double-blind, placebocontrolled trial of the Ginkgo biloba extract EGb 761 (R) in dementia. Dementia and Geriatric Cognitive Disorders, 11, 230-237.

Li, L., Dongfeng, C., Desmond, R., Rahman, A., Lah, J. L., Levey, A. I., et al. (2009). Cognitive performance and plasma levels of homocysteine, vitamin $\mathrm{B}_{12}$, folate and lipids in patients with Alzheimer Disease. Dementia and Geriatric Cognitive Disorders, 26, 384-390.

Luchsinger, J. A., Tang, M., Shea, S., \& Mayeux, R. (2003). Antioxidant vitamin intake and risk of Alzheimer Disease. Archives of Neurology, 60, 203-208.

Lukiw, W. J., \& Bazan, N. G. (2008). Docosahexanoic acid and the aging brain. Journal of Nutrition, 138, 2510-2514.

Lukiw, W. J., Cui, J. G., Marcheselli, V. L., Bodker, M., Botkjaer, A., Gotlinger, K., et al. (2005). A role for docosahexaenoic acid-derived neuroprotein D1 in neural cell survival and Alzheimer disease. Journal of Clinical Investigation, 115, 2774-2783.

Maclennan, K. M., Darlington, C. L., \& Smith, P. E. (2002). The CNS effects of Ginkgo biloba extracts and ginkgolide B. Progress in Neurobiology, 67, 235-257. 
Maxwell, C. J., Hicks, M. S., Hogan, D. B., Basran, J., \& Elby, E. M. (2005). Supplemental use of antioxidant vitamins and subsequent risk of cognitive decline and dementia. Dementia and Geriatric Cognitive Disorders, 20, 45-51.

Mazza, M., Pomponi, M., Janiri, L., Bria, P., \& Mazza, S. (2007). Omega-3 fatty acids and antioxidants in neurological and psychiatric diseases: An overview. Progress in NeuroPsychopharmacology \& Biological Psychiatry, 31, 12-26.

McGahon, B. M., Martin, D. S. D., Horrobin, D. F., \& Lynch, M. A. (1999). Age-related changes in synaptic function: Analysis of the effect of dietary supplementation with $\omega-3$ fatty acids. Neuroscience, 94, 305-314.

Mooijaart, S. P., Gussekloo, J., Frolich, M., Jolles, J., Stott, D. J., Westendorp, R. G. J., et al. (2005). Homocysteine, vitamin B-12, and folic acid and the risk of cognitive decline in old age: the Leiden 85-Plus Study. American Journal of Clinical Nutrition, 82, 866-871.

Moriguchi, T., Greiner, R. S., \& Salem, N. (2000). Behavioural deficits associated with dietary induction of decreased brain docosahexaenoic acid concentration. Journal of Neurochemistry, $75,2563-2573$.

Morris, M. C., Evans, D. A., Bienias, J. L., Tangney, C. C., \& Wilson, R. S. (2002). Vitamin E and cognitive decline in older persons. Archives of Neurology, 59, 1125-1132.

Morris, M. C., Evans, D. A., Schneider, J. A., Tangney, C. C., Bienias, J. L., \& Aggarwal, N. T. (2006). Dietary folate and vitamins B-12 and B-6 not associated with incident Alzheimer's disease. Journal of Alzheimer's Disease, 9, 435-443.

Morris, M. C., Evans, D. A., Tangney, C. C., Bienias, J. L., \& Wilson, R. S. (2005). Fish consumption and cognitive decline with age in a large community study. Archives of Neurology, 62, 1849-1853. 
Mozaffarian, D., \& Rimm, E. B. (2006). Fish intake, contaminants, and human health: Evaluating the risks and benefits. Journal of the American Medical Association, 296, 1885-1899.

Oken, B. S., Storzbach, D. M., \& Kaye, J. A. (1998). The efficacy of Ginkgo biloba on cognitive function in Alzheimer disease. Archives of Neurology, 55, 1409-1415.

Papandreou, M. A., Dimakopoulou, A., Linardaki, Z. I., Cordopatis, P., Klimis-Zacas, D., Margarity, M., et al. (2009). Effect of a polyphenol-rich blueberry extract on cognitive performance of mice, brain antioxidant markers and acetylcholinesterase activity. Behavioural Brain Research, 198, 352-358.

Perneczky, R., Pohl, C., Sorg, C., Hartmann, J., Tosic, N., Grimmer, T., et al. (2006). Impairment of activities of daily living requiring memory or complex reasoning as part of the MCI syndrome. International Journal of Geriatric Psychiatry, 21, 158-162.

Perrig, W. J., Perrig, P., \& Stahelin, H. B. (1997). The relation between antioxidants and memory performance in the old and very old. Journal of the American Geriatrics Society, 45, 718-724.

Ravaglia, G., Forti, P., Maioli, F., Montesi, F., Rietti, E., Pisacane, N., et al. (2007). Risk factors for dementia: data from the Conselice Study of Brain Aging. Archives of Gerontology and Geriatrics, S1, 311-320.

Rébeillé, F., Ravanel, S., Marquet, A., Mendel, R. R., Smith, A. G., \& Warren, M. J. (2007). Roles of vitamins B5, B8, B12 and molybdenum cofactor at cellular and organism levels. Natural Product Reports, 24, 949-962.

Ruxton, C. H. S., Reed, S. C., Simpson, M. J. A., \& Millington, K. J. (2007). The health benefits of omega-3 polyunsaturated fatty acids: a review of the evidence. Journal of Human Nutrition and Dietetics, 20, 275-285. 
Sanders, T. A. B. (2000). Polyunsaturated fatty acids in the food chain in Europe. American Journal of Clinical Nutrition, 71, 176S-178S.

Schulz, R. (2007). Homocysteine as a biomarker for cognitive dysfunction in the elderly. Current Opinion in Clinical Nutrition and Metabolic Care, 10, 718-723.

Seshadri, S. (2006). Elevated plasma homocysteine levels: Risk factor or risk marker for the development of dementia and Alzheimer's disease? Journal of Alzheimer's Disease, 9, 393398.

Shukitt-Hale, B., Carey, A., Simon, L., Mark, D. A., \& Joseph, J. A. (2006). Effects of Concord grape juice on cognitive and motor deficits in aging. Nutrition, 22, 295-302.

Shukitt-Hale, B., Lau, F. C., \& Joseph, J. A. (2009). Berry fruit supplementation and the aging brain. Journal of Agricultural and Food Chemistry, 56, 636-641.

Tangney, C. C., Tang, Y. X., Evans, D. A., \& Morris, M. C. (2009). Biochemcial indicators of vitamin B-12 and folate insufficiency and cognitive decline. Neurology, 72, 361-367.

Tassino, M., Campos, T. F., \& Guerra, R. O. (2009). Homocysteine (Hcy) and cognitive performance in a population sample of elderly Brazlians. Archives of Gerontology and Geriatrics, 48, 142-145.

van Dongen, M. C. J. M., van Rossum, E., Kessels, A. G. H., Sielhorst, H. J. G., Knipschild, P. G. (2000). The efficacy of ginkgo for elderly people with dementia and age-associated memory impairment: New results of a randomized clinical trial. Journal of the American Geriatrics Society, 48, 1183-1194.

Wengreen, H. J., Munger, R. G., Corcoran, C. D., Zandi, P., Hayden, K. M, Fotuhi, M., et al. (2007). Antioxidant intake and cognitive function of elderly men and women: The cache county study. Journal of Nutrition Health \& Aging, 11, 230-237. 
Whalley, L. J., Deary, I. J., Starr, J. M., Wahle, K. W., Rance, K. A., Bourne, V. J., et al. (2008). n3 fatty acid erythrocyte membrane content, APOE $\varepsilon 4$, and cognitive variation: an observational follow-up study in late adulthood. American Journal of Clinical Nutrition, 87, 449-454.

Youdim, K. A., Martin, A., \& Joseph, J. A. (2000). Essential fatty acids and the brain: possible health implications. International Journal of Developmental Neuroscience, 18, 383-399.

Yuen, A. W. C., Sander, J. W., Fluegel, D., \& Patsalos, P. N. (2005). Omega-3 fatty acid supplementation in patients with chronic epilepsy: A randomized trial. Epilepsy Behavior, 7, 253-258.

Zandi, P. P., Anthony, J. C., Khachaturian, A. S., Stone, S. V., Gustafson, D., Tschanz, J. T., et al. (2004). Reduced risk of Alzheimer Disease in users of antioxidant vitamin supplements: The Cache County Study. Archives of Neurology, 61, 82-88. 